\title{
Development of rosuvastatin flexible lipid- based nanoparticles: promising nanocarriers for improving intestinal cells cytotoxicity
}

\author{
Tarek A. Ahmed ${ }^{1,2}$ (D)
}

\begin{abstract}
Background: Rosuvastatin (RSV) is a poorly water-soluble drug that has an absolute oral bioavailability of only $20 \%$. The aim of this work was to prepare a positively charged chitosan coated flexible lipid-based vesicles (chitosomes) and compare their characteristics to the corresponding negatively charged flexible liposomal nanoparticles (NPs) in order to develop new RSV nanocarrier systems.

Methods: Three formulation factors affecting the development of chitosomes nano-formulation were optimized for their effects on the particles size, entrapment efficiency (EE) and zeta potential. The optimized flexible chitosomes and their corresponding liposomal NPs were characterized for morphology, in vitro release, flexibility and intestinal cell viability. The half maximum inhibitory concentrations (IC50) for both formulations were calculated.

Results: The drug to lipid molar ratio, edge activator percent and the chitosan concentration were significantly affecting the characteristics of NPs. The optimized chitosomes nano-formulation exhibited larger size, higher EE and greater zeta potential value when compared to the corresponding liposomal NPs. Both formulations showed a spherical shape nanostructure with a marked outer shell for the chitosomes nano-formulation. Chitosomes illustrated an extended drug release profile when compared with the corresponding liposomal NPs and the prepared drug suspension. Flexibility of both vesicles was confirmed with superiority of liposomal NPs over chitosomes. RSV loaded chitosomes nano-formulation exhibited lower IC50 values and higher therapeutic window while liposomal NPs were compatible with the intestinal cells.

Conclusions: RSV loaded chitosomes nano-formulation could be considered as a promising nanocarrier system with a marked cytotoxic activity while, RSV loaded liposomal NPs are suitable nanocarrier to improve RSV activity in treatment of cardiovascular disorders.
\end{abstract}

Keywords: Rosuvastatin, Optimization, Chitosomes, Liposomes, cell viability, Cytotoxicity

\section{Background}

Rosuvastatin (RSV), a member of statins, is used to prevent cardiovascular disorders by decreasing the lowdensity lipoprotein (LDL) cholesterol. It is the most effective hypolipidemic agent of the statins group and has been assigned the name super-statin $[4,6]$. Similar to

\footnotetext{
Correspondence: dr_tarek_nour@yahoo.com; tabdelnapy@kau.edu.sa ${ }^{1}$ Department of Pharmaceutics, Faculty of Pharmacy, King Abdulaziz University, Jeddah 21589, Kingdom of Saudi Arabia

${ }^{2}$ Department of Pharmaceutics and Industrial Pharmacy, Faculty of Pharmacy, Al-Azhar University, Cairo, Egypt
}

other statins, the mechanism of action of RSV is attributed to competitive inhibition of the enzyme 3-hydroxy3-methyl-glutaryl-CoA (HMG-CoA) reductase [30]. RSV has a low water solubility and exhibits a limited solubility in the gastrointestinal fluids [11]. The drug is subjected to extensive first pass metabolism after oral administration. Accordingly, the oral bioavailability of RSV is approximately $20 \%$. The maximum RSV plasma concentration is reached in about 3 to $5 \mathrm{~h}$. The drug is $88 \%$ bound to plasma protein mainly to serum albumin. It is probable that about $25 \%$ of the orally administered

(c) The Author(s). 2020 Open Access This article is distributed under the terms of the Creative Commons Attribution 4.0 International License (http://creativecommons.org/licenses/by/4.0/), which permits unrestricted use, distribution, and 
dose is absorbed [27, 45]. RSV is mainly metabolized by the liver CYP2C9. It is $90 \%$ excreted in feces and the drug elimination half-life is nearly $19 \mathrm{~h}$.

Different pharmaceutical formulation strategies have been used to enhance the bioavailability of drugs that are suffering from poor aqueous solubility. These include size reduction, the use of cosolvents and surfactants, solid dispersion and inclusion complexation techniques, salt formation and prodrug approaches. Moreover, formation of colloidal drug delivery systems such as solid lipid nanoparticles (NPs), polymeric based NPs, lipid based NPs, microemulsion formation and selfmicroemulsifying drug delivery systems has been reported [26, 31]. Flexible liposomes have been assigned the name "Transfersomes" and these NPs constitute a class of the lipid based NPs which consist of phospholipid(s) and a single chain surfactant [12]. The presence of surfactant (edge activator) promotes flexibility of these NPs by reducing the rigidity of the phospholipid bilayer and so render these nanocarriers ultradeformable vesicles [1]. Due to their successful delivery of a wide variety of pharmacologically active agents, these ultra-deformable NPs have attracted too much research interest $[1,9,12,13,18,20,22,25,39]$.

Chitosan is a linear polysaccharide polymer that is obtained from chitin shells of shrimp and other crustaceans after treatment with an alkaline substance such as sodium hydroxide. It is consists of a randomly distributed $\beta$ - $(1 \rightarrow 4)$-linked D-glucosamine unit and $\mathrm{N}$-acetylD-glucosamine unit. The former unit is the deacetylated part while the latter is the acetylated portion in the chitosan structure. It is the only naturally occurring alkaline polysaccharide polymer with good biocompatibility and biodegradability [43]. Different chitosan based NPs have been developed and reported to be an effective drug delivery systems due to their efficient drug encapsulation, protection against enzymatic degradation, enhanced drug permeation and controlled release action [2]. Moreover, NPs coated with chitosan have been reported in the literature to enhance stability and drug loading, controlling the drug release and maximizing the efficacy. Chitosan-coated poly (lactic-co-glycolic acid) NPs, magnetic NPs coated with chitosan, chitosan-coated cobalt ferrite NPs, chitosan-coated solid lipid NPs and chitosan-coated liposomes are common examples $[5,8$, $14,17,21,24,42]$.

In this study, a promising RSV flexible lipid-based nanocarriers, liposomal NPs and chitosomes nanoformulation, were successfully prepared and characterized for vesicles size, zeta potential, entrapment efficiency, morphology, flexibility, in vitro drug release, cell viability and cytotoxicity. The half maximum inhibitory (IC50) concentrations for both nanocarrier systems were calculated to investigate their therapeutic window. The stability, pharmacokinetic and pharmacodynamic activity of these drug loaded flexible lipid-based NPs will be investigated, in our upcoming work, after loading into the suitable drug delivery system.

\section{Materials and methods}

Rosuvastatin (RSV) was obtained as a gift from the Saudi Arabian Japanese Pharmaceuticals Co. Ltd. (SAJA) (Jeddah, KSA). Dicetyl phosphate (DCP) and methanol were purchased from Fisher Scientific (Pittsburgh, PA, USA). Tween 80, low molecular weight chitosan and glacial acetic acid were procured from Sigma-Aldrich (St. Louis, MI, USA). L- $\alpha$ phosphatidylcholine (95\%) (soy), molecular weight $=775.037$ (average based on fatty acid distribution in product) was purchased from Avanti $i^{\circ}$ polar lipids, INC. (Alabaster, Alabama, USA). All other materials used were of analytical grade.

\section{Box-Behnken experimental design}

StatGraphics Centurion XV version 15.2.05 software, StatPoint Technologies, Inc., (Warrenton, VA, USA) was employed to study the effect of three independent factors affecting the development of RSV chitosan-coated flexible lipid-based nanocarrier (chitosomes nanoformulation). The drug to phospholipid molar ratio $\left(\mathrm{X}_{1}\right)$, the surfactant (edge activator) concentration $\left(\mathrm{X}_{2}\right)$ and the chitosan coating solution concentration $\left(\mathrm{X}_{3}\right)$ were studied for their effect on vesicle size $\left(\mathrm{Y}_{1}\right)$, entrapment efficiency $\left(\mathrm{Y}_{2}\right)$ and zeta potential $\left(\mathrm{Y}_{3}\right)$. Fifteen formulations were proposed, and their composition is illustrated in Table 1 . The studied independent factors namely; $X_{1}$, $\mathrm{X}_{2}$ and $\mathrm{X}_{3}$ were used at 1:1-1:4 drug to phospholipid molar ratios, $0.01-0.04 \%(\mathrm{w} / \mathrm{v})$ based on the total formulation volume and $0.2-0.6 \%(\mathrm{w} / \mathrm{v})$, respectively. The goal was to minimize $Y_{1}$ and maximize both $Y_{2}$ and $Y_{3}$.

\section{Preparation of RSV flexible-lipid based NPs}

Lipid film hydration technique was used to prepare the NPs formulations according to the method previously reported in our previously published work but with little modifications [1]. Briefly, $100 \mathrm{mg}$ of RSV and the calculated amount of phospholipid, edge activator (tween 80) and DCP (15\% w/w of the total lipid) were dispersed in $100 \mathrm{~mL}$ methanol in a Buchi rotavapor evaporating flask. The mixture was subjected to sonication using Ultrawave Ltd., CF3 2EY water bath sonicator (Cardif, UK) until homogenous dispersion was obtained. The organic solvent, methanol, was evaporated at a temperature of $50{ }^{\circ} \mathrm{C}$ under reduced pressure and continuous rotation using Buchi Rotavapor R-200, Buchi labortechink AG, CH-9230 (Flawi, Switzerland). The obtained lipid film deposited inside the flask wall was kept for $24 \mathrm{~h}$ in a vacuum oven of Thermo Fisher Scientific, model 6505 (Oakwood Village, OH, USA) to ensure complete 
Table 1 Composition of rosuvastatin chitosomes nanoparticles formulations and the obtained values for the studied responses

\begin{tabular}{|c|c|c|c|c|c|c|c|}
\hline \multirow[t]{2}{*}{ Run } & \multirow{2}{*}{$\begin{array}{l}X_{1} \\
(M R)\end{array}$} & \multirow{2}{*}{$\begin{array}{l}X_{2} \\
(\%)\end{array}$} & \multirow{2}{*}{$\begin{array}{l}X_{3} \\
(\%)\end{array}$} & \multicolumn{2}{|c|}{$Y_{1}$} & \multirow{2}{*}{$\begin{array}{l}Y_{2} \\
(\%)\end{array}$} & \multirow{2}{*}{$\begin{array}{l}Y_{3} \\
(m V)\end{array}$} \\
\hline & & & & Size (nm) & PDI & & \\
\hline 1 & 1.0 & 0.01 & 0.4 & $239.48 \pm 5.33$ & $0.344 \pm 0.065$ & $90.88 \pm 1.65$ & $12.66 \pm 1.58$ \\
\hline 2 & 4.0 & 0.04 & 0.4 & $225.27 \pm 6.59$ & $0.425 \pm 0.095$ & $86.94 \pm 4.94$ & $18.10 \pm 3.38$ \\
\hline 3 & 2.5 & 0.04 & 0.2 & $112.19 \pm 2.90$ & $0.288 \pm 0.009$ & $85.14 \pm 5.04$ & $-1.83 \pm 0.55$ \\
\hline 4 & 2.5 & 0.01 & 0.6 & $554.33 \pm 11.06$ & $0.573 \pm 0.045$ & $94.59 \pm 1.62$ & $26.74 \pm 0.26$ \\
\hline 5 & 2.5 & 0.04 & 0.6 & $507.40 \pm 18.14$ & $0.581 \pm 0.051$ & $91.97 \pm 4.89$ & $26.07 \pm 1.90$ \\
\hline 6 & 4.0 & 0.01 & 0.4 & $295.40 \pm 5.11$ & $0.258 \pm 0.023$ & $88.75 \pm 3.99$ & $10.70 \pm 0.16$ \\
\hline 7 & 4.0 & 0.025 & 0.6 & $547.33 \pm 20.09$ & $0.511 \pm 0.024$ & $92.79 \pm 1.76$ & $28.87 \pm 1.39$ \\
\hline 8 & 2.5 & 0.01 & 0.2 & $163.13 \pm 3.29$ & $0.391 \pm 0.053$ & $87.94 \pm 2.04$ & $-8.14 \pm 0.51$ \\
\hline 9 & 1.0 & 0.025 & 0.6 & $535.33 \pm 43.12$ & $0.543 \pm 0.053$ & $93.22 \pm 1.24$ & $27.23 \pm 0.31$ \\
\hline 10 & 1.0 & 0.025 & 0.2 & $132.77 \pm 4.46$ & $0.439 \pm 0.061$ & $87.61 \pm 2.07$ & $-10.07 \pm 1.26$ \\
\hline 11 & 1.0 & 0.04 & 0.4 & $219.53 \pm 6.36$ & $0.354 \pm 0.071$ & $90.63 \pm 2.15$ & $13.15 \pm 0.75$ \\
\hline 12 & 4.0 & 0.025 & 0.2 & $132.97 \pm 2.11$ & $0.318 \pm 0.022$ & $84.78 \pm 3.09$ & $-6.92 \pm 0.16$ \\
\hline 13 & 2.5 & 0.025 & 0.4 & $255.83 \pm 8.37$ & $0.394 \pm 0.128$ & $85.44 \pm 2.21$ & $11.26 \pm 2.04$ \\
\hline 14 & 2.5 & 0.025 & 0.4 & $252.30 \pm 3.84$ & $0.318 \pm 0.088$ & $86.38 \pm 3.03$ & $11.83 \pm 2.67$ \\
\hline 15 & 2.5 & 0.025 & 0.4 & $259.77 \pm 3.69$ & $0.382 \pm 0.043$ & $85.15 \pm 4.07$ & $14.87 \pm 1.89$ \\
\hline
\end{tabular}

Abbreviations: $X_{1}$ Drug to phospholipid, $X_{2}$ Surfactant concentration, $X_{3}$ Coating solution concentration, $Y_{1}$ Particle size (nm, $Y_{2}$ Entrapment efficiency (\%), $Y_{3}$ Zeta potential (mV), MR Molar ratio, PDI Poly dispersity index

evaporation of methanol. The hydration medium, $50 \mathrm{~mL}$ of phosphate buffer $\mathrm{pH} 7$, was added to the flask that was kept shaking in the rotavapor for $30 \mathrm{~min}$ at $50^{\circ} \mathrm{C}$. The obtained flexible liposomal dispersion was subjected to probe sonication using Sonics Vibra cell, VCX 750; Sonics \& Materials, Inc. (Newtown, CT, USA) for 10 min at an amplitude of $60 \%$.

For the coating step, three chitosan solutions $(0.4,0.8$ and $1.2 \% \mathrm{w} / \mathrm{v}$ ) were prepared by dissolving the calculated amount of chitosan in $0.5 \% \mathrm{v} / \mathrm{v}$ acetic acid solution. According to the formulation composition, $50 \mathrm{~mL}$ of the specified chitosan solution was added dropwise to an equal volume of the prepared flexible liposomal dispersion over a magnetic stirrer at $1200 \mathrm{rpm}$ for $2 \mathrm{~h}$ at room temperature. The prepared chitosan-coated flexible liposomal NPs (chitosomes nano-formulation) of 0.2, 0.4 or $0.6 \% \mathrm{w} / \mathrm{v}$ chitosan were left over night in the refrigerator for complete curing of the NPs.

A specified volume of the obtained flexible liposomal NPs was separated and characterized, as will described in the following section, to compare their features with the corresponding chitosomes nano-formulation.

\section{Characterization of the flexible lipid-based nanoparticles Particle size distribution and zeta potential}

The particle size, polydispersity index (PDI) and zeta potential for the prepared fifteen NPs formulations were determined $(n=3)$ using Malvern Zetasizer Nano ZSP, Malvern Panalytical Ltd. (Malvern, United Kingdom). Dynamic light scattering with non-invasive backscatter optics was the technique utilized in the measurement.
Entrapment efficiency (EE)

The obtained RSV loaded flexible lipid-based nanocarriers (liposomal NPs and chitosomes nano-formulation) were centrifuged at $20000 \mathrm{rpm}$ for $1 \mathrm{~h}$ at $4{ }^{\circ} \mathrm{C}$ using 3 K30 Sigma Laboratory centrifuge (Ostrode, Germany) to separate the free unentrapped drug. The supernatant was filtered through $0.2 \mu \mathrm{m}$ Millipore filter and the drug concentration was estimated spectrophotometrically at $242 \mathrm{~nm}$ using $6705 \mathrm{UV} / \mathrm{Vis}$ spectrophotometer, Jenway (Stone, UK). The EE (\%) for each formulation was calculated indirectly using the following equation.

$$
E E(\%)=\frac{\text { Total amount of drug used }- \text { Calculated amount of free drug }}{\text { Total amount of drug used }} \times 100
$$

Accuracy of the spectrophotometric method and its freedom from any possible interference by the formulation components were verified. Recovery testing for RSV concentration in different drug solutions containing the studied excipients was verified.

\section{Box-Behnken experimental design statistical analysis}

Data obtained for particle size, EE and zeta potential for the prepared flexible chitosomes nano-formulation were statistically analyzed to identify the main, interaction and quadratic effects significantly affecting each response. The effect was considered significant at $p$-value less than 0.05 . An optimized formulation that achieve the study goal was proposed. 


\section{Preparation and characterization of the optimized formulation}

The proposed optimized NPs formulation was prepared and characterized for size, PDI, EE and zeta potential as described above. The observed values were compared to the predicted ones and the residual was calculated.

\section{Morphological study}

Few drops of the optimized flexible-chitosomes nanoformulation was mounted on a carbon coated grid and left for $5 \mathrm{~min}$ to allow better adsorption of the NPs on the carbon film. Excess liquid was removed by a filter paper. Few drops of $1 \%$ phosphotungstic acid was added and the sample was examined under the transmission electron microscopy (TEM), Model JEM-1230, JOEL (Tokyo, Japan). Morphology of the corresponding liposomal NPs formulation was also studied and compared to the chitosomes nano-formulation.

\section{Fourier transforms infrared (FT-IR)}

The FT-IR spectra of pure RSV, phospholipid and chitosan samples were studied using a Nicolet Is10 of Thermo Scientific, Inc., (Waltham, MA). The spectra of the prepared liposomal NPs and chitosomes nanoformulation were also investigated to identify any possible changes in the drug physicochemical characteristics following development of the flexible lipid-based NPs formulations. The FT-IR spectra of all the studied samples were recorded in the range of $4000-400 \mathrm{Cm}^{-1}$.

\section{In vitro release study}

The in vitro release of RSV from the prepared liposomal NPs, chitosomes nano-formulation and pure drug suspension was studied as previously reported [5]. A quantity of each preparation containing $9 \mathrm{mg}$ of drug was placed in a firmly sealed dialysis bag (Sigma-Aldrich Inc.) of a molecular weight cut-off $14 \mathrm{kDa}$. The dialysis bag was immersed in a glass bottle containing $400 \mathrm{~mL}$ of $\mathrm{pH}$ 7.4. The bottles were kept in a shaking water bath (Model 1031; GFL Corporation, Burgwedel, Germany) at $37^{\circ} \mathrm{C}$ and $100 \mathrm{rpm}$. The parameters of the in vitro release study were selected to achieve the sink condition. Aliquots of $2 \mathrm{~mL}$ were taken from the receptor compartment at predetermined time intervals with immediate replacement. The quantity of RSV in the withdrawn samples was determined spectrophotometrically at 242 $\mathrm{nm}$. The experiment was done in triplicate for each formulation and mean values were calculated.

\section{Nanoparticles flexibility}

To evaluate the flexibility of the prepared NPs, the extrusion method was used [3]. Concisely, the optimized chitosomes nano-formulation and the corresponding liposomal NPs were separately extruded through $0.1 \mathrm{~mm}$ pore size membrane filter under reduced pressure. The size of both NPs was measured before and after the extrusion process. The flexibility was estimated as the percent change in the NPs size according to the following equation:

Flexibility $=\frac{\text { Size of the NPs before extrusion-Size of the NPs after extrusion }}{\text { Size of the NPs before extrusion }} \times 100$

\section{Cell viability and cytotoxicity assay}

This test aimed to determine the effect of the prepared RSV lipid-based NPs formulations on the intestinal cell viability and cytotoxicity. The potential effects of both formulations on the human colorectal (HCT-116) cells were assessed by 3-(4,5-dimethylthiazol-2-yl)2,5 -diphenyl tetrazolium bromide (MTT) assay. Cells were seeded on 96-well plates $\left(1 \times 10^{4}\right.$ cells/well $)$ and incubated at $37{ }^{\circ} \mathrm{C}$ under a humidified atmosphere of $5 \% \mathrm{CO}_{2}$ for 24 $\mathrm{h}$. The cell medium was then changed to serum free medium (SFM) alone or SFM containing RVS loaded liposomal NPs and chitosomes nano-formulation in different drug concentrations $(1.95,3.91,7.81,15.63,31.21$, $62.5,125$ and $250 \mu \mathrm{M})$ and incubated for $72 \mathrm{~h}$ at $37^{\circ} \mathrm{C}$. Each formulation was compared with a drug-free carrier as a negative control. After incubation, SFM in the control and test wells were replaced by $100 \mu \mathrm{L} /$ well of MTT solution $(0.5 \mathrm{mg} / \mathrm{ml})$ in PBS and incubated at $37^{\circ} \mathrm{C}$ for another $3 \mathrm{~h}$. The MTT solution was removed and the purple formazan crystals formed at the bottom of the wells were dissolved using $100 \mu \mathrm{L}$ DMSO/well with shaking for $2 \mathrm{~h}$ at room temperature. The intensity of the color obtained was measured at $549 \mathrm{~nm}$ using a microplate reader (ELX 800; Bio-Tek Instruments, Winooski, VT, USA). Data, expressed as the percentages of viable cells, were compared to the survival of a control group. Values of the half maximal inhibitory concentration $\left(\mathrm{IC}_{50}\right)$ were also estimated. Cells treated with DMSO only were defined as $100 \%$.

\section{Results}

A great number of pharmacologically active compounds do not reach the commercialization step simply because of their limited oral bioavailability that is attributed to inadequate dissolution rate. A substantial problem that is currently confronting the pharmaceutical industry for drugs of limited aqueous solubility is mainly attributed to their limited dissolution rate [7]. Also, during the first-pass metabolism phenomenon, the fraction of drug administered is lost during the absorption process due to the liver and/or gut wall metabolism. Accordingly, the drug concentration is greatly reduced before reaching the systemic circulation [35].

Chitosan-based NPs have been successfully developed and reported to have wide applications especially in oral 
drug delivery $[15,19,28,41]$. The reported benefits include; enhancing transport of active pharmaceutical ingredients across the intestinal epithelial cell layer, protection of insulin against degradation in the gastrointestinal fluid, enhancement of bioavailability and improvement of aqueous drug solubility. In this study, flexible liposomal NPs and their corresponding chitosomes nano-formulation loaded with RSV were prepared to develop new nanocarrier systems suitable to investigate their role in intestinal cells cytotoxicity and improving RSV bioavailability.

\section{Characterization of the flexible lipid-based NPs formulations}

Flexible liposomal NPs were prepared using the lipid film hydration technique utilizing L- $\alpha$ phosphatidylcholine, dicetyl phosphate and tween 80 as the main component of the liposomes membrane, negative charge inducing agent and edge activator, respectively. These flexible liposomal NPs were subsequently coated with chitosan to produce chitosan-coated flexible liposomes that have been assigned the name chitosomes nanoformulation. Both NPs formulations have been characterized for size, PDI, EE and zeta potential. Results for these parameters are illustrated in Table 1 . The diameter size of the obtained chitosomes nano-formulation was in the range of $112.19 \pm 2.90-554.33 \pm 11.06 \mathrm{~nm}$, the PDI was between $0.258 \pm 0.023-0.581 \pm 0.051$, the EE was ranged between $84.78 \pm 3.09-94.59 \pm 1.62 \%$ and the obtained zeta potential value, which indicates surface charge of the particles, was in the range of $(-10.07 \pm$
1.26) - (+ $28.87 \pm 1.39) \mathrm{mV}$. Characterization of the corresponding flexible liposomal NPs revealed a vesicle size between $96.73 \pm 2.45-282.33 \pm 10.22 \mathrm{~nm}$, PDI values in the range $0.3213 \pm 0.0290-0.5423 \pm 0.0236$, an EE between $71.44 \pm 2.48-79.57 \pm 1.27 \%$ and negative zeta potential values of $(-8.84 \pm 0.66)-(-12.73 \pm 0.81)$.

\section{Experimental design statistical analysis results}

Statistical analysis for the effect of the independent factors $\left(\mathrm{X}_{1}, \mathrm{X}_{2}\right.$ and $\left.\mathrm{X}_{3}\right)$ on the dependant responses $\left(\mathrm{Y}_{1}, \mathrm{Y}_{2}\right.$ and $\mathrm{Y}_{3}$ ) was accomplished by multiple regression analysis and two- way analysis of variance (ANOVA) using the StatGraphics software. Regression analysis is a statistical processes that estimate and analyze the relationships between a dependent variable and one or more of the independent variables. The two-way ANOVA aims to assess the main, interaction and quadratic effect of the independent variable on one dependent response. Accordingly, estimated effect of factors, F-ratios, and associated $P$-values were calculated and the obtained data are presented in Table 2. The sign of the estimated effect is an indication of a synergistic (positive sign) or antagonistic (negative sign) effect of this factor on the studied response. F-ratio is used to compare between the observed and expected averages. An F-ratio greater than 1 specifies a location effect and hence the $P$-value is used to report the significant level. If the obtained results for the $P$-value, for an independent factor, differs from zero and is less than 0.05 , this factor is significantly affecting the studied response.

Table 2 Estimated effects of factors, F-ratios, and associated P-values for the studied responses $Y_{1}-Y_{3}$

\begin{tabular}{|c|c|c|c|c|c|c|c|c|c|}
\hline \multirow[t]{2}{*}{ Factor } & \multicolumn{3}{|l|}{$Y_{1}$} & \multicolumn{3}{|l|}{$Y_{2}$} & \multicolumn{3}{|l|}{$Y_{3}$} \\
\hline & Estimated effect & F-ratio & $P$-Value & Estimated effect & F-ratio & $P$-Value & Estimated effect & F-ratio & P-Value \\
\hline$X_{1}$ & 21.415 & 6.68 & $0.0492^{\mathrm{a}}$ & -1.67 & 6.08 & 0.0569 & 1.568 & 0.75 & 0.4262 \\
\hline$x_{2}$ & -45.985 & 30.80 & $0.0026^{\mathrm{a}}$ & -1.825 & 7.26 & $0.0431^{\mathrm{a}}$ & 1.638 & 0.82 & 0.4073 \\
\hline$x_{3}$ & 714.135 & 2252.15 & $0.00001^{\mathrm{a}}$ & 14.160 & 132.45 & $0.0001^{\mathrm{a}}$ & 35.187 & 114.48 & $0.0001^{\mathrm{a}}$ \\
\hline$x_{1} X_{1}$ & -8.209 & 0.68 & 0.4472 & 3.333 & 16.76 & $0.0094^{\mathrm{a}}$ & 0.067 & 0.00 & 0.9767 \\
\hline$x_{1} x_{2}$ & -25.09 & 6.88 & $0.0470^{\mathrm{a}}$ & -0.78 & 0.99 & 0.3645 & 3.455 & 2.73 & 0.1593 \\
\hline$x_{1} x_{3}$ & 7.375 & 0.38 & 0.5644 & 1.5 & 2.35 & 0.1856 & -0.944 & 0.13 & 0.7328 \\
\hline$x_{2} x_{2}$ & -13.884 & 1.94 & 0.2220 & 3.953 & 23.58 & $0.0047^{\mathrm{a}}$ & 1.932 & 0.79 & 0.4154 \\
\hline$x_{2} x_{3}$ & 2.506 & 0.04 & 0.8423 & 0.113 & 0.01 & 0.9129 & -4.363 & 2.79 & 0.1559 \\
\hline$x_{3} x_{3}$ & 266.368 & 293.08 & $0.00001^{\mathrm{a}}$ & 7.115 & 31.27 & $0.0025^{a}$ & -9.092 & 7.15 & $0.0442^{a}$ \\
\hline$R^{2}(\%)$ & 99.87 & & & 97.99 & & & 99.09 & & \\
\hline Adj. $R^{2}(\%)$ & 99.64 & & & 94.38 & & & 97.47 & & \\
\hline SE of Est. & 9.57 & & & 0.782 & & & 2.091 & & \\
\hline Mean AE & 4.82 & & & 0.406 & & & 1.058 & & \\
\hline
\end{tabular}

Abbreviations: $X_{1}$ Drug to phospholipid, $X_{2}$ Surfactant concentration, $X_{3}$ Coating solution concentration, $Y_{1}$ Particle size (nm), $Y_{2}$ Entrapment efficiency (\%), $Y_{3}$ Zeta potential $(\mathrm{mV}), X_{1} X_{2}, X_{1} X_{3}$, and $X_{2} X_{3}$ are the interaction effects of the studied factors, $X_{1} X_{1}, X_{2} X_{2}$ and $X_{3} X_{3}$ are the quadratic effects of factors, SE Standard error, $A E$ Absolute error

Note: ${ }^{\mathrm{a}}$ indicates significant effect of this factor on the studied response 
Effect of the drug to phospholipid molar ratio $\left(X_{1}\right)$ on the studied responses $\left(Y_{1}-Y_{3}\right)$

Results of the statistical analysis illustrated in Table 2, indicated that the drug to phospholipid molar ratio $\left(\mathrm{X}_{1}\right)$ was significantly affecting the particle size $\left(\mathrm{Y}_{1,}\right)$ at $P_{-}$ values of 0.0492 . The pareto chart, displayed in Fig. 1, also confirmed this finding. A reference line is displayed in this chart. Any bar that extends after this line confirms the significant effect of this factor on the studied response. As indicated from the sign of the estimated effect and the pareto chart, $\mathrm{X}_{1}$ exhibited an agonistic effect on $\mathrm{Y}_{1}$.

\section{Effect of the surfactant concentration $\left(X_{2}\right)$ on the studied responses $\left(Y_{1}-Y_{3}\right)$}

The surfactant concentration $\left(\mathrm{X}_{2}\right)$ was significantly affecting the particle size $\left(\mathrm{Y}_{1}\right)$ and the EE $\left(\mathrm{Y}_{2}\right)$ at $P$ values of 0.0026 and 0.0431 , respectively as indicated by the pareto (Fig. 1) and the values of the estimated factors effects. $\mathrm{X}_{2}$ was antagonistically affecting $\mathrm{Y}_{1}$ and $Y_{2}$. Hence, increasing the surfactant concentration decreased the particle size and the EE of the prepared NPs.

\section{Effect of the chitosan solution concentration $\left(X_{3}\right)$ on the studied responses $\left(Y_{1}-Y_{3}\right)$}

It was noticed that the concentration of the chitosan solution $\left(\mathrm{X}_{3}\right)$ was significantly affecting all the studied response $\left(Y_{1}-Y_{3}\right)$. This factor illustrated a synergistic, positive, effect on $Y_{1}, Y_{2}$ and $Y_{3}$. Bars in the pareto chart, Fig. 1, confirmed this finding.

It was noticed from the ANOVA that the interaction effect of $\mathrm{X}_{3} \mathrm{X}_{3}$ significantly affected all the studied variables. $X_{1} X_{1}$, and $X_{2} X_{2}$ were significantly affecting $Y_{2}$, while $X_{1} X_{2}$ was affecting $Y_{1}$.

The mathematical model for the studied responses was generated and the polynomial equations that best fit the models are:

$$
\begin{aligned}
\mathrm{Y}_{1}= & 167.497+25.282 \mathrm{X}_{1}+1236.66 \mathrm{X}_{2} \\
& -735.615 \mathrm{X}_{3}-1.82426 \mathrm{X}_{1}{ }^{2}-557.556 \mathrm{X}_{1} \mathrm{X}_{2} \\
& +9.83333 \mathrm{X}_{1} \mathrm{X}_{3}-30853.7 \mathrm{X}_{2}{ }^{2}+334.167 \mathrm{X}_{2} \mathrm{X}_{3} \\
& +2130.95 \mathrm{X}_{3}{ }^{2} . \\
\mathrm{Y}_{2}= & 102.625-4.82704 \mathrm{X}_{1}-464.259 \mathrm{X}_{2}-33.9708 \mathrm{X}_{3} \\
& +0.740741 \mathrm{X}_{1}{ }^{2}-17.3333 \mathrm{X}_{1} \mathrm{X}_{2}+2.0 \mathrm{X}_{1} \mathrm{X}_{3} \\
& +8785.19 \mathrm{X}_{2}{ }^{2}+15.0 \mathrm{X}_{2} \mathrm{X}_{3}+56.9167 \mathrm{X}_{3}{ }^{2} .
\end{aligned}
$$

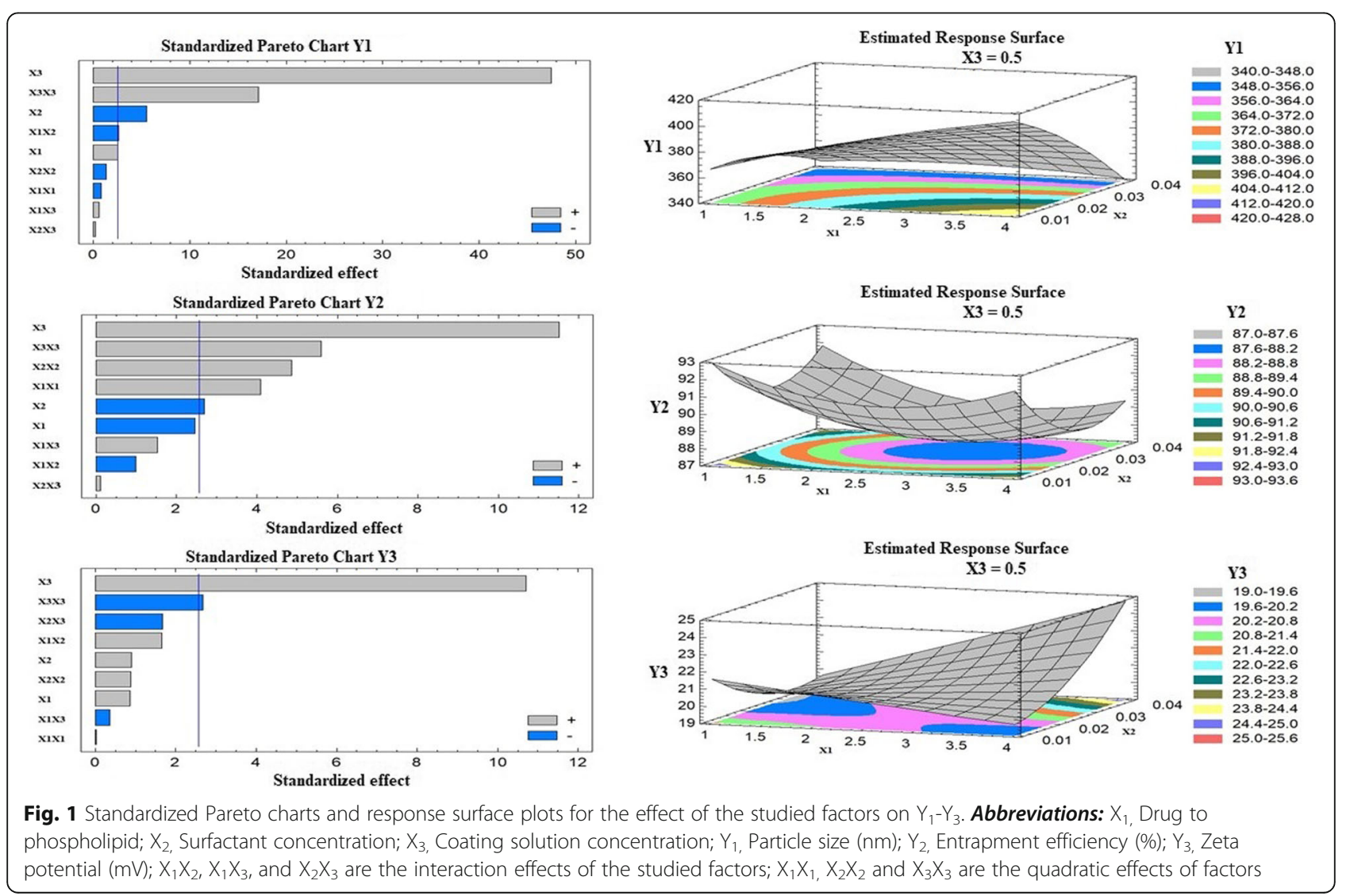


Table 3 The optimum levels and values, and desirability levels and values for the studied factors and responses

\begin{tabular}{|c|c|c|c|c|c|c|}
\hline \multirow[t]{2}{*}{ Factors } & \multirow[t]{2}{*}{ Low } & \multirow[t]{2}{*}{ High } & \multicolumn{3}{|c|}{ Optimum level for each response } & \multirow{2}{*}{$\begin{array}{l}\text { Optimum } \\
\text { desirability } \\
\text { level }\end{array}$} \\
\hline & & & $Y_{1}=99.12 \mathrm{~nm}$ & $Y_{2}=95.99 \%$ & $Y_{3}=28.85 \mathrm{mV}$ & \\
\hline $\mathrm{X}_{1}$ (MR) & 1.0 & 4.0 & 1.0 & 1.0 & 1.0 & 1.0 \\
\hline$X_{2}(\%)$ & 0.01 & 0.04 & 0.04 & 0.01 & 0.01 & 0.01 \\
\hline$X_{3}(\%)$ & 0.2 & 0.6 & 0.2 & 0.6 & 0.59 & 0.47 \\
\hline \multirow[t]{2}{*}{ Responses } & \multirow[t]{2}{*}{ Goal } & & \multicolumn{3}{|c|}{ Optimum desirability } & \\
\hline & & & Predicted values & \multicolumn{2}{|c|}{ Observed values } & Residual \\
\hline$Y_{1}(\mathrm{~nm})$ & \multicolumn{2}{|l|}{ Minimize } & 331.09 & \multicolumn{2}{|l|}{342.33} & 11.24 \\
\hline$Y_{2}(\%)$ & \multicolumn{2}{|l|}{ Maximize } & 92.31 & \multicolumn{2}{|l|}{94.01} & 1.7 \\
\hline$Y_{3}(\mathrm{mV})$ & \multicolumn{2}{|l|}{ Maximize } & 19.39 & \multicolumn{2}{|l|}{21.22} & 1.83 \\
\hline
\end{tabular}

Abbreviations: $X_{1}$ Drug to phospholipid, $X_{2}$ Surfactant concentration, $X_{3}$ Coating solution concentration, $Y_{1}$ Particle size, $Y_{2}$ Entrapment efficiency, $Y_{3}$ Zeta potential, MR Molar ratio

$$
\begin{aligned}
\mathrm{Y}_{3}= & -36.8913-0.841852 \mathrm{X}_{1}-61.1574 \mathrm{X}_{2} \\
& +160.79 \mathrm{X}_{3}+0.0148148 \mathrm{X}_{1}{ }^{2} \\
& +76.7778 \mathrm{X}_{1} \mathrm{X}_{2}-1.25833 \mathrm{X}_{1} \mathrm{X}_{3} \\
& +4292.59 \mathrm{X}_{2}{ }^{2}-581.667 \mathrm{X}_{2} \mathrm{X}_{3}-72.7292 \mathrm{X}_{3}{ }^{2} .
\end{aligned}
$$

Figure 1 also illustrates the three-dimensional estimated response surface plots that demonstrate the effect of two independent factors on a studied response when the value of the third factor was kept at intermediate level. Individual analysis for the effect of the studied variables on the $Y_{1}$ indicated that to prepare flexible chitosomes nano-formulation of $99.12 \mathrm{~nm}$, the optimum levels for $X_{1}, X_{2}$ and $X_{3}$ should be 1.0, 0.04 and 0.2, respectively as illustrated in Table 3 . To obtain vesicles of 95.99\% EE, the optimum levels for $X_{1}, X_{2}$ and $X_{3}$ should be 1.0, 0.01 and 0.6 , respectively. Flexible chitosomes nano-formulation with a zeta potential value of 28.85 $\mathrm{mV}$ could be obtained at 1.0, 0.01 and 0.59 of $\mathrm{X}_{1}, \mathrm{X}_{2}$ and $X_{3}$, respectively. After analyzing the multiple effect of the studied variables on $Y_{1}, Y_{2}$ and $Y_{3}$, it was assumed that the optimum desirability that achieve the smallest particle size, highest $\mathrm{EE}$ and highest zeta potential values could be achieved at $X_{1}, X_{2}$ and $X_{3}$ levels of 1.0, 0.01 and 0.47 , respectively. An optimized chitosomes nanoformulation formulation that contains these values was prepared, characterized and the values for predicted and observed values and their residuals are depicted in Table 3 . The corresponding flexible liposomal NPs showed an average size of $230.34 \pm 8.73 \mathrm{~nm}$, PDI value of $0.508 \pm$ 0.075 , zeta potential value of $-10.29 \pm 0.46 \mathrm{mV}$ and $\mathrm{EE}$ of $78.13 \pm 0.54 \%$.

\section{Morphological characterization}

The vesicular nature of the liposomal NPs and chitosomes nano-formulation was confirmed after investigation of their morphological characteristics as depicted in Fig. 2. Both formulations showed spherical shape particles with a marked outer shell for chitosomes nano-
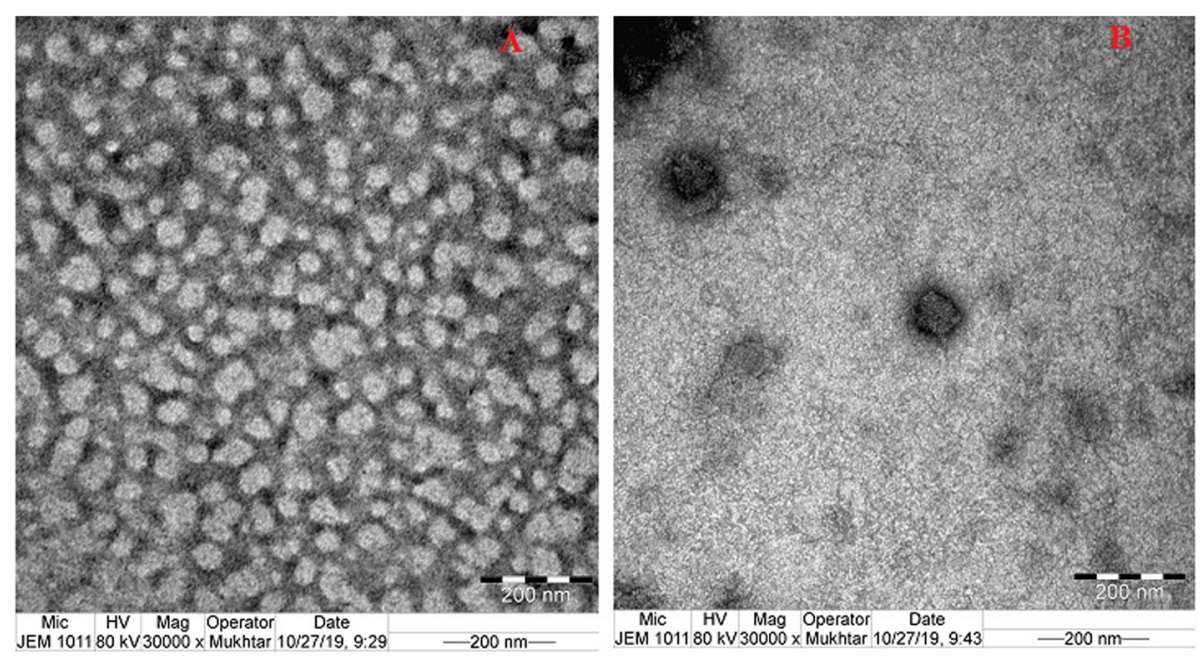

Fig. 2 TEM images of rosuvastatin liposomal NPs (a) and chitosomes nano-formulation (b) 
formulation. Addition of chitosan during preparation of the lipid-based vesicles resulted in deposition of this cationic polymer on the particles outer surface, the effect that lead to formation of thick outer membrane. Moreover, chitosomes nano-formulation exhibited larger size compared to the corresponding liposomal NPs which is in a good agreement with the results obtained from the particle size analysis.

\section{Fourier transforms infrared (FT-IR)}

In this work, we have studied the FT-IR spectrum for RSV loaded into different lipid-based nano-dispersed formulation without drying. We aimed to identify the drug physicochemical changes in the developed liposomal NPs and chitosomes nano-formulation without any further modifications in the formulation nature.

The FT-IR spectrum of pure RSV (Fig. 3) illustrated a broad band for $\mathrm{O}-\mathrm{H}$ stretching at $3380 \mathrm{~cm}^{-1}$ and a band at $2920 \mathrm{~cm}^{-1}$ for $=\mathrm{C}-\mathrm{H}$ stretching. Another two drug peaks were detected at $1550 \mathrm{~cm}^{-1}$ and $1515 \mathrm{~cm}^{-1}$ corresponding to $\mathrm{C}=\mathrm{C}$ stretching and $\mathrm{N}-\mathrm{H}$ bending, respectively. Asymmetric and symmetric bending vibration of the drug $\mathrm{CH}_{3}$ group were noticed at $1485 \mathrm{~cm}^{-1}$ and $1380 \mathrm{~cm}^{-1}$, respectively. The asymmetric vibration of $\mathrm{S}=$ $\mathrm{O}$ was observed at $1330 \mathrm{~cm}^{1}$. The bending vibrations for $\mathrm{C}-\mathrm{H}$ and $\mathrm{C}-\mathrm{F}$ stretching were identified at $1230 \mathrm{~cm}^{-1}$ and $1155 \mathrm{~cm}^{-1}$, respectively.

The spectrum of the $\mathrm{L}-\alpha$ phosphatidylcholine illustrated a broad peak at $3354 \mathrm{~cm}^{-1}$ corresponding to the stretching vibration of the hydroxyl $(\mathrm{OH})$ group. A sharp characteristic band between 2700 and $2950 \mathrm{~cm}^{-1}$ was originated from the $\mathrm{C}-\mathrm{H}$ stretching vibration of the aliphatic methyl group. Another peak at $1735 \mathrm{~cm}^{-1}$ that assigned to $\mathrm{C}=\mathrm{O}$ stretching was also detected. The $\mathrm{PO}_{2}$ antisymmetric double bond stretching bands was noticed at $1250 \mathrm{~cm}^{-1}$.
Chitosan showed a broad band in the range of 3300-2900 $\mathrm{cm}^{-1}$ corresponded to the amine and hydroxyl groups. A peak at $2876 \mathrm{~cm}^{-1}$ that is attributed to $-\mathrm{OH}$ stretching; a characteristic band of the carbonyl $(\mathrm{C}=\mathrm{O})$ stretching of the secondary amide was detected at $1655 \mathrm{~cm}^{-1}$, and the bending vibrations of the $\mathrm{N}-\mathrm{H}$ ( $\mathrm{N}$-acetylated residues, amide II band) was observed at $1599 \mathrm{~cm}^{-1}$ [38] [38] [38] [38] [38] [38] [38]. Other peaks at 1423 and $1381 \mathrm{~cm}^{-1}$ that belong to the $\mathrm{N}-\mathrm{H}$ stretching of the amide and ether, respectively were also detected.

The spectrum of the liposomal NPs and chitosomes nano-formulation confirmed the physical interaction between the studied components and effective encapsulation of RSV in the prepared nanovesicles. Broadening, overlapping, weak and/or disappearance of some bands in the spectra of the NPs formulation were noticed. These changes were observed for phospholipid bands between 2700 and $2950 \mathrm{~cm}^{-1}$, and at $1735 \mathrm{~cm}^{-1}$; for drug peaks at 1515 and $1330 \mathrm{~cm}^{1}$; for chitosan peaks at 1599, 1423 and $1381 \mathrm{~cm}^{-1}$. Phosphatidyl choline is a neutral or zwitterionic substance over a wide $\mathrm{pH}$ range from strongly acid to strongly alkaline.

\section{In vitro release study}

The in vitro release of RSV from the prepared liposomal NPs and chitosomes nano-formulation was studied and compared to that of a pure drug suspension using the dialysis bag technique. As depicted in Fig. 4, the release of RSV from the liposomal NPs illustrated a biphasic drug release pattern. An initial rapid drug release rate that was followed by a slow drug release pattern. The optimized flexible chitosomes nano-formulation exhibited a lower initial drug release, compared to the corresponding liposomal NPs, the effect that is explained by the high EE (chitosomes nano-formulation $E E=94.01 \%)$. A second

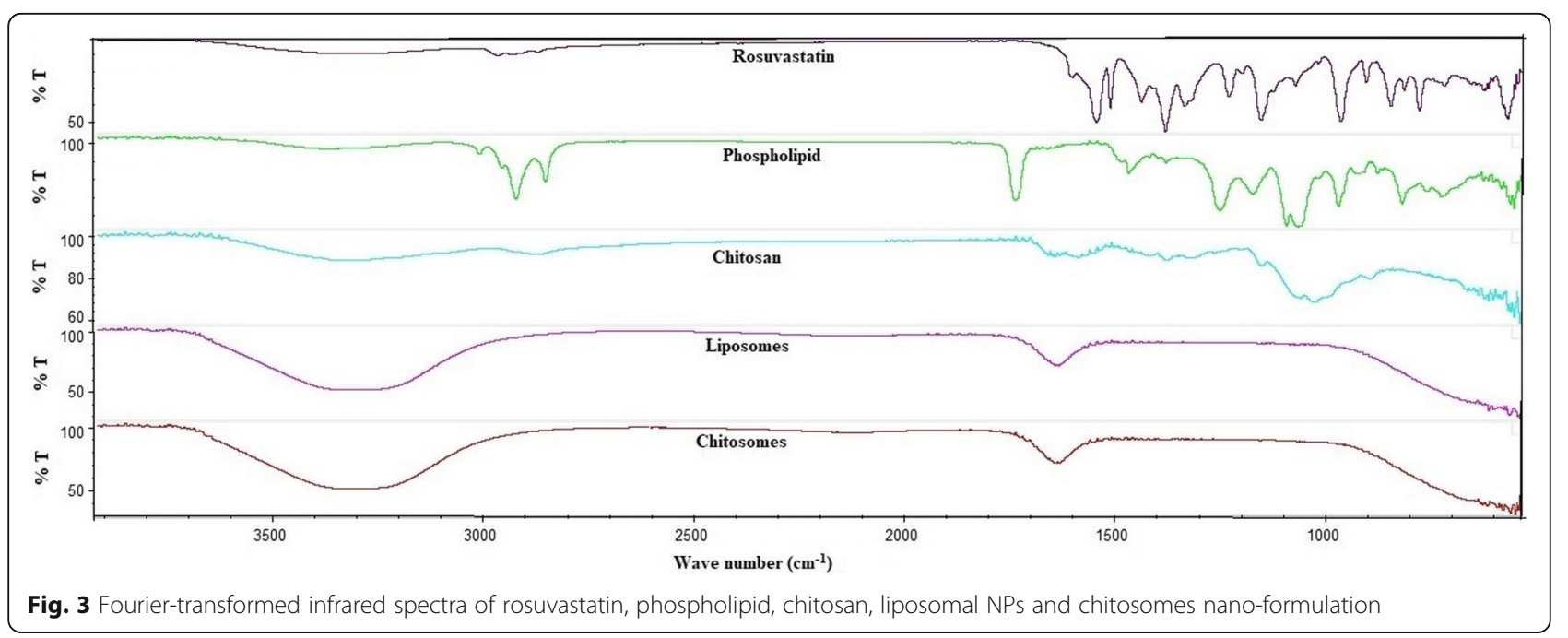




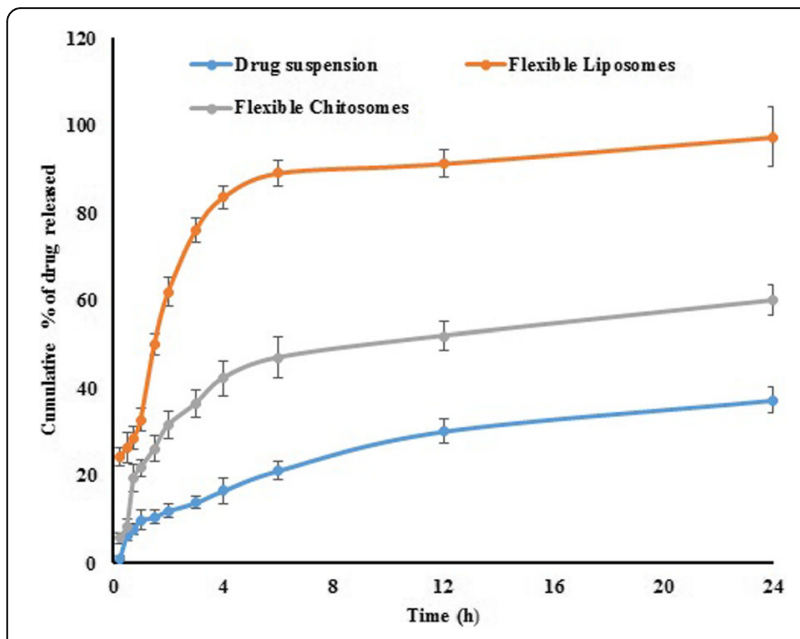

Fig. 4 In vitro release of rosuvastatin from pure drug suspension, liposomal NPs and chitosomes nano-formulation

sustained release stage was observed for both liposomal NPs and chitosomes nano-formulation. Drug suspension demonstrated an overall low drug release pattern, when compared to lipid-based NPs formulations, and smaller cumulative drug release due to the presence of the suspended drug particles in a coarse dispersion state.

\section{NPs flexibility}

The ability of the prepared nanovesicles to pass through $0.1 \mathrm{~mm}$ pore size membrane filter under reduced pressure was considered as a measurement of NPs flexibility. The prepared liposomal NPs and chitosomes nanoformulation revealed a flexibility value of 44.43 and $40.16 \%$, respectively.

\section{Cell viability and cytotoxicity assay}

Statins possess anticancer activity, against many cancer cells, under in vitro conditions in a time- and dosedependent manner [29]. Previous studies mentioned that RSV demonstrated a cytotoxic activity against thyroid, hepatic, breast, cervical and prostate cancer cell lines $[10,44]$. Another study illustrated the anti-melanoma properties of RSV [29]. The anticancer activity of statins is attributed to their ability to inhibit the mevalonate pathway, which leads to reduction of cholesterol synthesis, and to their ability to decrease the cellular levels of non-steroidal isoprenoids, geranylgeranyl pyrophosphate and farnesyl pyrophosphate. These effects result in failure of protein prenylation which affects carcinogenesis [29]. As far as we know, RSV activity against intestinal cells has not been studied to date.

To examine the biocompatibility and cytotoxic effects of plain and drug loaded liposomal NPs or chitosomes nano-formulation, HCT-116 cells were treated with different concentrations of these samples for 3 days and the MTT assay was performed to investigate the effect of these formulation on the viability of living cells. This test depends on the production of a colored formazan by the action of the viable cells' mitochondrial enzymes on MTT. Cells were exposed to increasing RSV concentrations of drug loaded liposomal NPs and chitosomes nano-formulation standardized at certain RSV concentrations. Cells were also incubated with blank liposomal NPs and chitosomes nano-formulation to exclude the effect of RSV. As shown in Fig. 5, cellular proliferation was inhibited in a dose-dependent manner of RVS. The inhibition difference between plain (drug free) chitosomes and liposomes treated with $250 \mu \mathrm{M}$ at $24 \mathrm{~h}$ was
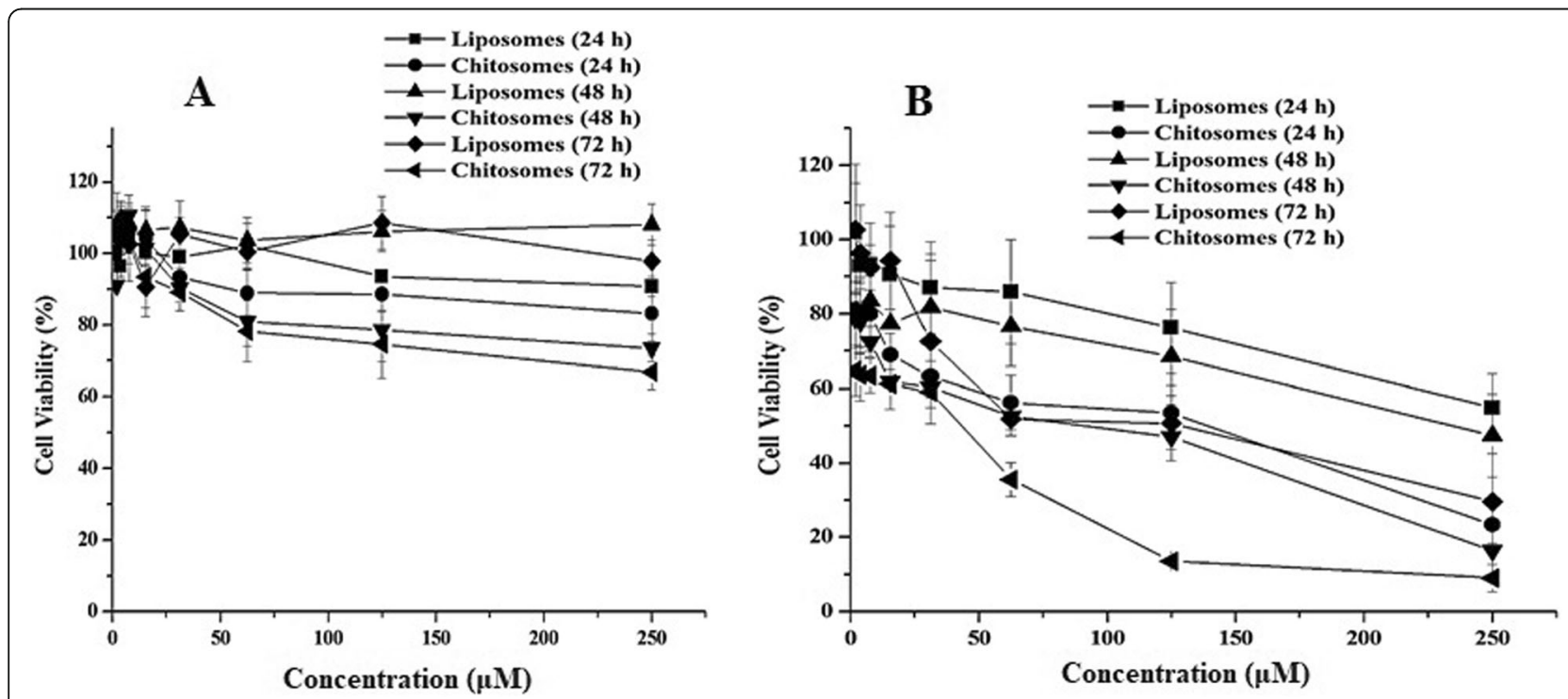

Fig. 5 Cell viability after treatment with free liposomal NPs and chitosomes nano-formulation (a), and following treatment with rosuvastatin loaded liposomal NPs and chitosomes nano-formulation (b) 
much less than its drug-loaded counterpart, the effect that could be attributed to the prominent drug cytotoxic effect at this concentration.

Interestingly, the IC50 values of chitosomes nanoformulation were found to be smaller than the corresponding liposomal NPs. The calculated IC50 values for chitosomes nano-formulation were about 142.5, 98.6 and $43.9 \mu \mathrm{M}$ after 24,48 and $72 \mathrm{~h}$ respectively, while that of liposomal NPs were 234.8, 218.8 and $131.7 \mu \mathrm{M}$ respectively, after the same.

\section{Discussion}

As the drug to phospholipid molar ratio was increased from 1: 1 to 1: 4, the particle size of the prepared NPs increased. At higher phospholipid load, the formation of multilamellar vesicles is favored, the effect that results in increasing the size of the prepared NPs. This explanation was previously mentioned by Harbi et al. during development of sertraline liposomes [23].

The effect of the surfactant concentration on the particle size could be attributed to the reduction of the surface tension of the media at higher surfactant concentration and so arrangement of the phospholipid in small vesicles as previously reported [5]. The decrease in the EE of the prepared vesicles that was observed at higher surfactant concentration could be attributed to the formation of micelles molecules that compete for the drug molecules with the lipid vesicles. This finding is in a good agreement with the work done by Patel et al., who reported a decrease in the EE of curcumin loaded transfersomes with increasing the surfactant concentration [33].

The particle size, EE and zeta potential of the drug loaded NPs were increased as the concentration of chitosan (coating) solution was increased. Addition of chitosan to the flexible liposomal vesicles resulted in coating of the NPs outer surface by an electrostatic interaction between the positively charged chitosan and the negatively charged NPs surface. This coating process resulted in an enlargement of the vesicles as previously stated [32, 46]. Deposition of more chitosan on the NPs surface was achieved at higher polymeric concentration, the effect that results in increasing the zeta potential value and promotion of more drug entrapment in the coated NPs. The electrostatic interaction between the negatively charged drug and the positively charged chitosan, that deposited on the NPs surface, may be another cause for the increase in drug EE at higher chitosan concentration.

Encapsulation of RSV in the phospholipid molecules, adsorption of the DCP at the phospholipid molecules and chitosan coating of the flexible liposomal NPs may result in electrostatic interaction by weak van der Waals force of attraction or dipole-dipole and hydrogen bond formation. This finding was confirmed after FTIR characterization and was previously reported by Rudra et al., during development and characterization of nanoliposomes loaded with doxorubicin [36].

The amount of drug that was released from the liposomal NPs during the early stage is mainly attributed to the un-encapsulated drug (liposomal NPs EE $=78.13 \pm$ $0.54 \%$ ), drug adsorbed on the NPs surface and to the drug permeated from the prepared NPs. Chitosomes nano-formulation illustrated an extended drug release pattern due to the presence of chitosan in the outer shell which delayed the diffusion of RSV into the release medium. This effect was previously reported by Chen et al., who illustrated the role of chitosan coating on the behavior of flurbiprofen-loaded chitosan-coated deformable liposomes [16]. The second sustained release stage that was observed for both liposomal NPs and chitosomes nano-formulation could be attributed to encapsulation of RSV within the lipid shell that allows slow drug release from the lipid matrix. This finding is in a good agreement with that reported by Perez et al., during development of amphotericin B ultra-deformable liposomes [34]. After $24 \mathrm{~h}$, the values for drug release from liposomal NPs, chitosomes nano-formulation and pure drug suspension were $97.54 \pm 3.37,59.98 \pm 3.47$ and $37.28 \pm 2.86 \%$, respectively.

The flexibility values of both formulations indicated the elasticity of the prepared NPs. The effect that is attributed to the presence of the edge activator component. The presence of the edge activator weakens the phospholipid bilayer and render the nano-vesicle ultradeformable. Chitosomes nano-formulation demonstrated less flexibility than the corresponding liposomal NPs, the effect that is attributed to the chitosan coating process.

The cellular proliferation was inhibited in a dosedependent manner of RVS which is an indication for the reduction in cell viability upon increasing the drug concentration in the prepared liposomal NPs and chitosomes nano-formulation. This finding is in a good agreement with earlier studies for other statins such as lovastatin [40] and simvastatin [37]. The smaller IC50 values of chitosomes nano-formulation when compared to the corresponding liposomal NPs indicate a gradual release of RSV from the NPs phospholipid bilayers and the significant effect of chitosan layer on cell viability when compared to liposomal NPs. Positivity of the NPs outer shell demonstrated a marked cytotoxic effect which was also obvious with plain (drug free) chitosomes nano-formulation but to a lesser extent. This finding indicates the higher therapeutic window of RSV chitosomes nano-formulation. Accordingly, chitosomes nano-formulation could be considered as a good nanocarrier for RSV cytotoxic activity while drug loaded liposomal NPs could be considered as a suitable carrier to enhance the activity of RSV in treatment of cardiovascular diseases, but more investigations are required. 


\section{Conclusions}

The optimization design was successfully used to develop RSV lipid-based nanocarriers of spherical shape. Chitosomes nano-formulation illustrated a distinct outer shell membrane and larger size vesicles when compared to the corresponding liposomal NPs. Both formulations illustrated a biphasic drug release profile. Chitosomes nano-formulation exhibited a lower initial and more extended drug release pattern when compared to liposomal NPs. Chitosomes nano-formulation demonstrated smaller IC50 values than the corresponding liposomal NPs. Both NPs formulations exhibited an anticancer activity in a time- and dose-dependent manner. Chitosomes nano-formulation are a promising nanocarrier for RSV cytotoxicity while liposomal NPs are appropriate carrier to enhance RSV bioavailability in treatment of hyperlipidemia.

\section{Abbreviations}

ANOVA: Analysis of variance; DCP: Dicetyl phosphate; EE: Entrapment efficiency; FT-IR: Fourier transforms infrared; HMG-CoA: 3-hydroxy-3-methylglutaryl-CoA; IC50: The half maximum inhibitory concentrations; LDL: Lowdensity lipoprotein; MTT: 3-(4,5-dimethylthiazol-2-yl)2,5 -diphenyl tetrazolium bromide; NPs: Nanoparticles; PDI: Polydispersity index; RSV: Rosuvastatin; TEM: Transmission electron microscopy; $X_{1}$ : Drug to phospholipid; $X_{2}$ : Surfactant concentration; $X_{3}$ : Coating solution concentration; $Y_{1}$ : Particle size $(n m) ; Y_{2}$ : Entrapment efficiency (\%); $Y_{3}$ : Zeta potential $(m V) ; X_{1} X_{2}, X_{1} X_{3}$, and $X_{2} X_{3}$ are the interaction effects of the studied factors; $X_{1} X_{1}, X_{2} X_{2}$ and $X_{3} X_{3}$ are the quadratic effects of factors

\section{Acknowledgments}

The authors, therefore, acknowledge with thanks DSR for technical and financial support.

\section{Declarations}

Author declares that there is no conflict of interests.

\section{Author's contributions}

TAA designed the study, analyzed the data obtained and wrote the manuscript. The author read and approved the final manuscript.

\section{Funding}

This project was funded by the Deanship of Scientific Research (DSR) at King Abdulaziz University, Jeddah, under grant no. G: 102-166-1440.

\section{Availability of data and materials}

All data obtained and analyzed during this work are included in this article. Extra information is available upon reasonable request from the corresponding author.

\section{Ethics approval}

No animal or clinical studies are applicable in this work.

\section{Consent for publication}

Not applicable.

\section{Competing interests}

Rosuvastatin (RSV) was obtained as a gift from the Saudi Arabian Japanese Pharmaceuticals Co. Ltd. (SAJA) (Jeddah, KSA).

\section{Received: 29 November 2019 Accepted: 12 February 2020}

Published online: 21 February 2020

\section{References}

1. Ahmed TA. Preparation of transfersomes encapsulating sildenafil aimed for transdermal drug delivery: Plackett-Burman design and characterization. J
Liposome Res [Internet]. 2015;25(1):1-10 Available from: http:// informahealthcare.com/doi/abs/10.3109/08982104.2014.950276.

2. Ahmed TA, Aljaeid BM. Preparation, characterization, and potential application of chitosan, chitosan derivatives, and chitosan metal nanoparticles in pharmaceutical drug delivery. Drug Des Devel Ther. 2016; 10:483-507.

3. Ahmed TA, El-Say KM, Aljaeid BM, Fahmy UA, Abd-Allah FI. Transdermal glimepiride delivery system based on optimized ethosomal nano-vesicles: Preparation, characterization, in vitro, ex vivo and clinical evaluation. Int J Pharm [Internet] Elsevier B V. 2016;500(1-2):245-54 Available from: http:// linkinghub.elsevier.com/retrieve/pii/S0378517316300187.

4. Ahmed TA, Mussari MA, Abdel-Hady SES, El-Say KM. An optimized surfactant-based PEG-PLCL in situ gel formulation for enhanced activity of Rosuvastatin in Poloxamer-induced Hyperlipidemic rats. Drug Des Devel Ther. 2019;13:4035-51.

5. Alomrani A, Badran M, Harisa Gl, ALshehry M, Alhariri M, Alshamsan A, et al. The use of chitosan-coated flexible liposomes as a remarkable carrier to enhance the antitumor efficacy of 5-fluorouracil against colorectal cancer. Saudi Pharm J. 2019;27(5):603-11.

6. Alshora DH, Ibrahim MA, Elzayat E, Almeanazel OT, Alanazi F. Rosuvastatin calcium nanoparticles: Improving bioavailability by formulation and stabilization codesign. Mukherjee A, editor. PLoS One [Internet] Public Library of Science; 2018;13(7):e0200218. Available from: https://dx.plos.org/1 0.1371/journal.pone.0200218, [cited 2019 Sep 2]

7. Amidon GL, Lobenberg R. Modern bioavailability, bioequivalence and biopharmaceutics classi ${ }^{\oplus} \mathrm{Cation}$ system. New scienti ${ }^{\oplus} \mathrm{C}$ approaches to international regulatory standards. Eur J Pharm Biopharm. 2000;50:3-12.

8. Angeli de Lima I, Maissar Khalil N, Toyomi Tominaga T, Lechanteur A, Sarmento B, Mara Mainardes R. Mucoadhesive chitosan-coated PLGA nanoparticles for oral delivery of ferulic acid. Artif Cells Nanomed Biotechnol [Internet]. 2018;46:993-1002 Available from: https://www.tandfonline.com/ action/journallnformation?journalCode=ianb20, [cited 2019 Sep 3].

9. Badr-Eldin SM, Ahmed OAA. Optimized nano-transfersomal films for enhanced sildenafil citrate transdermal delivery: ex vivo and in vivo evaluation. Drug Des Devel Ther. 2016;10:1323-33.

10. Brown M, Hart C, Tawadros T, Ramani V, Sangar V, Lau M, et al. The differential effects of statins on the metastatic behaviour of prostate cancer. Br J Cancer [Internet] Nature Publishing Group. 2012;106(10):1689-96 Available from: http://www.ncbi.nlm.nih.gov/pubmed/22531631, [cited 2019 Oct 7].

11. Butt S, Hasan SMF, Hassan MM, Alkharfy KM, Neau SH. Directly compressed rosuvastatin calcium tablets that offer hydrotropic and micellar solubilization for improved dissolution rate and extent of drug release. Saudi Pharm J [Internet] King Saud University. 2019;27(5):619-28 Available from: https://doi.org/10.1016/j.jsps.2019.03.002.

12. Cevc G, Blume $\mathrm{G}$. New, highly efficient formulation of diclofenac for the topical, transdermal administration in ultradeformable drug carriers, Transfersomes. Biochim Biophys Acta Biomembr [Internet]. 2001;1514(2): 191-205 Available from: http://www.sciencedirect.com/science/article/pii/ S0005273601003698, [cited 2015 Apr 28].

13. Cevc G, Blume G, Schätzlein A. Transfersomes-mediated transepidermal delivery improves the regio-specificity and biological activity of corticosteroids in vivo1Dedicated to the late Dr. Henri Ernest Bodde.1. J Control Release. 1997;45(3):211-26.

14. Channarong S, Chaicumpa W, Sinchaipanid N, Mitrevej A. Development and evaluation of chitosan-coated liposomes for oral DNA vaccine: the improvement of Peyer's patch targeting using a polyplex-loaded liposomes. AAPS PharmSciTech. 2011;12(1):192-200.

15. Chen C-H, Lin Y-S, Wu S-J, Mi F-L. Mutlifunctional nanoparticles prepared from arginine-modified chitosan and thiolated fucoidan for oral delivery of hydrophobic and hydrophilic drugs. Carbohydr Polym [Internet]. 2018;193: 163-72 Available from: http://www.ncbi.nlm.nih.gov/pubmed/29773368, [cited 2020 Jan 16].

16. Chen H, Pan H, Li P, Wang H, Wang X, Pan W, et al. The potential use of novel chitosan-coated deformable liposomes in an ocular drug delivery system. Colloids Surfaces B Biointerfaces [Internet] Elsevier. 2016;143:455-62 Available from: https://www.sciencedirect.com/science/article/pii/S092 7776516302168?via\%3Dihub, [cited 2019 Sep 28].

17. Chronopoulou L, Massimi M, Giardi MF, Cametti C, Devirgiliis LC, Dentini M, et al. Chitosan-coated PLGA nanoparticles: A sustained drug release strategy for cell cultures. Colloids Surfaces B Biointerfaces [Internet]. Elsevier. 2013; 
103:310-7 Available from: https:/www.sciencedirect.com/science/article/pii/ S0927776512006364, [cited 2019 Sep 3].

18. Duangjit S, Opanasopit P, Rojanarata T, Ngawhirunpat T. Characterization and In Vitro Skin Permeation of Meloxicam-Loaded Liposomes versus Transfersomes. J Drug Deliv [Internet]. 2011;2011:418316 Available from: http://www.pubmedcentral.nih.gov/articlerender.fcgi?artid=3066552\&tool= pmcentrez\&rendertype=abstract, [cited 2015 May 18].

19. Feng C, Wang Z, Jiang C, Kong M, Zhou X, Li Y, et al. Chitosan/ocarboxymethyl chitosan nanoparticles for efficient and safe oral anticancer drug delivery: in vitro and in vivo evaluation. Int J Pharm [Internet]. 2013; 457(1):158-67 Available from: http://www.ncbi.nIm.nih.gov/pubmed/240291 70, [cited 2020 Jan 16].

20. Ghanbarzadeh S, Arami S. Enhanced transdermal delivery of diclofenac sodium via conventional liposomes, ethosomes, and transfersomes. Biomed Res Int. 2013;2013:616810. https://doi.org/10.1155/2013/616810.

21. Gingasu D, Mindru I, Patron L, lanculescu A, Vasile E, Marinescu G, et al. Synthesis and Characterization of Chitosan-Coated Cobalt Ferrite Nanoparticles and Their Antimicrobial Activity. J Inorg Organomet Polym Mater [lnternet]. Springer US. 2018;28(5):1932-41 Available from: http://ink. springer.com/10.1007/s10904-018-0870-3, [cited 2019 Sep 3].

22. Gupta PN, Mishra V, Rawat A, Dubey P, Mahor S, Jain S, et al. Non-invasive vaccine delivery in transfersomes, niosomes and liposomes: a comparative study. Int J Pharm. 2005;293(1-2):73-82.

23. Harbi I, Aljaeid B, El-Say KM, Zidan AS. Glycosylated sertraline-loaded liposomes for brain targeting: QbD study of formulation Variabilities and brain transport. AAPS PharmSciTech. 2016;17(6):1404-20.

24. Khan N, Ameeduzzafar KK, Bhatnagar A, Ahmad FJ, Ali A. Chitosan coated PLGA nanoparticles amplify the ocular hypotensive effect of forskolin: Statistical design, characterization and in vivo studies. Int J Biol Macromol [Internet]. Elsevier. 2018;116:648-63 Available from: https:/www. sciencedirect.com/science/article/pii/S0141813018306068?via\%3Dihub, [cited 2019 Sep 3]

25. Kim A, Lee EH, Choi SH, Kim CK. In vitro and in vivo transfection efficiency of a novel ultradeformable cationic liposome. Biomaterials. 2004;25(2):305-13.

26. Krishnaiah Y. Pharmaceutical Technologies for Enhancing Oral Bioavailability of poorly soluble drugs. J Bioequiv Availab. 2010;02(02):28-36.

27. Li Y, Jiang X, Lan K, Zhang R, Li X, Jiang Q. Pharmacokinetic Properties of Rosuvastatin After Single-Dose, Oral Administration in Chinese Volunteers: A Randomized, Open-Label, Three-Way Crossover Study. Clin Ther [Internet]. Elsevier. 2007;29(10):2194-203 Available from: https://www.sciencedirect.com/ science/article/pii/S0149291807003293?via\%3Dihub, [cited 2018 Oct 17].

28. Maity S, Mukhopadhyay P, Kundu PP, Chakraborti AS. Alginate coated chitosan core-shell nanoparticles for efficient oral delivery of naringenin in diabetic animals_-an in vitro and in vivo approach. Carbohydr Polym Elsevier Ltd. 2017;170:124-32.

29. Maj M, Czajkowski R, Zegarska B, Kowaliszyn B, Pokrywczynska M, Drewa T. Anti-proliferative and cytotoxic activity of rosuvastatin against melanoma cells. Postep Dermatologii i Alergol. 2016;33(4):257-62.

30. Nicholls SJ, Libby P, Raichlen JS, Ballantyne CM, Davignon J, Erbel R, et al. Effect of very high-intensity statin therapy. JAMA. 2006;295(13):1556-65.

31. Noolkar SB, Jadhav NR, Bhende SA, Killedar SG. Solid-state characterization and dissolution properties of meloxicam-moringa coagulant-PVP ternary solid dispersions. AAPS PharmSciTech [Internet]. 2013;14(2):569-77 Available from: http://www.pubmedcentral.nih.gov/articlerender.fcgi?artid=3665984 \&tool=pmcentrez\&rendertype=abstract, [cited 2016 Apr 11].

32. Park SN, Jo NR, Jeon SH. Chitosan-coated liposomes for enhanced skin permeation of resveratrol. J Ind Eng Chem [Internet]. Elsevier. 2014;20(4): 1481-5 Available from: https://www.sciencedirect.com/science/article/pii/ S1226086X13003468, [cited 2019 Sep 22].

33. Patel R, Singh SK, Singh S, Sheth NR, Gendle R. Development and characterization of curcumin loaded transfersome for transdermal delivery. J Pharm Sci Res. 2009;1(4):71-80.

34. Perez AP, Altube MJ, Schilrreff P, Apezteguia G, Celes FS, Zacchino S, et al. Topical amphotericin B in ultradeformable liposomes: Formulation, skin penetration study, antifungal and antileishmanial activity in vitro. Colloids Surfaces B Biointerfaces. Elsevier B.V. 2016;139:190-8.

35. Pond SM, Tozer TN. First-Pass Elimination. Clin Pharmacokinet [Internet]. 1984;9(1):1-25 Available from: http://www.ncbi.nlm.nih.gov/pubmed/636295 0, [cited 2019 Sep 12].

36. Rudra A, Deepa RM, Ghosh MK, Ghosh S, Mukherjee B. Doxorubicin-loaded phosphatidylethanolamine-conjugated nanoliposomes: in vitro characterization and their accumulation in liver, kidneys, and lungs in rats. Int J Nanomedicine [Internet]. Dove Press. 2010;5:811-23 Available from: http://www.ncbi.nlm.nih.gov/pubmed/21042545, [cited 2019 Oct 7].

37. Saito A, Saito N, Mol W, Furukawa H, Tsutsumida A, Oyama A, et al. Simvastatin inhibits growth via apoptosis and the induction of cell cycle arrest in human melanoma cells. Melanoma Res [Internet]. 2008;18(2):85-94 Available from: http://www.ncbi.nlm.nih.gov/pubmed/18337644, [cited 2019 Oct 17].

38. Sankalia MG, Mashru RC, Sankalia JM, Sutariya VB. Reversed chitosanalginate polyelectrolyte complex for stability improvement of alphaamylase: Optimization and physicochemical characterization. Eur J Pharm Biopharm [Internet]. 2007;65(2):215-32 Available from: http://www.ncbi.nlm. nih.gov/pubmed/16982178, [cited 2019 Mar 3].

39. Scognamiglio I, De Stefano D, Campani V, Mayol L, Carnuccio R, Fabbrocini $G$, et al. Nanocarriers for topical administration of resveratrol: A comparative study. Int J Pharm [Internet]. Elsevier B.V. 2013;440(2):179-87 Available from: http://dx.doi.org/10.1016/j.jpharm.2012.08.009.

40. Shellman YG, Ribble D, Miller L, Gendall J, Vanbuskirk K, Kelly D, et al. Lovastatin-induced apoptosis in human melanoma cell lines. Melanoma Res [Internet]. 2005;15(2):83-9 Available from: http://www.ncbi.nlm.nih.gov/ pubmed/15846140, [cited 2019 Oct 17].

41. Tsai L-C, Chen C-H, Lin C-W, Ho Y-C, Mi F-L. Development of mutlifunctional nanoparticles self-assembled from trimethyl chitosan and fucoidan for enhanced oral delivery of insulin. Int J Biol Macromol [Internet]. 2019;126: 141-50 Available from: http://www.ncbi.nlm.nih.gov/pubmed/30586591, [cited 2020 Jan 16].

42. Vieira ACC, Chaves LL, Pinheiro S, Pinto S, Pinheiro M, Lima SC, et al. Mucoadhesive chitosan-coated solid lipid nanoparticles for better management of tuberculosis. Int J Pharm [Internet]. Elsevier, Available from: https://www.sciencedirect.com/science/article/pii/S0378517317311262 ?via\%3Dihub, [cited 2019 Sep 3]. 2018;536(1):478-85.

43. Yu S, Xu X, Feng J, Liu M, Hu K. Chitosan and chitosan coating nanoparticles for the treatment of brain disease. Int J Pharm [Internet]. Elsevier. 2019;560:282-93 Available from: https://www.sciencedirect.com/ science/article/pii/S0378517319301358, [cited 2019 Sep 3].

44. Zeybek ND, Gulcelik NE, Kaymaz FF, Sarisozen C, Vural I, Bodur E, et al. Rosuvastatin induces apoptosis in cultured human papillary thyroid cancer cells. J Endocrinol [Internet]. 2011;210(1):105-15 Available from: https://joe. bioscientifica.com/view/journals/joe/210/1/105.xml, [cited 2019 Oct 7].

45. Zhang R, Li Y, Jiang $X$, Wang L. Pharmacokinetics and tolerability of multiple-dose rosuvastatin: An open-label, randomized-sequence, three-way crossover trial in healthy Chinese volunteers. Curr Ther Res [Internet]. Elsevier. 2009;70(5):392-404 Available from: https://www.sciencedirect.com/ science/article/pii/S0011393X09000903, [cited 2018 Oct 17].

46. Zhou F, Xu T, Zhao Y, Song H, Zhang L, Wu X, et al. Chitosan-coated liposomes as delivery systems for improving the stability and oral bioavailability of acteoside. Food Hydrocoll [Internet]. Elsevier; 2018 ;83:1724. Available from: https://www.sciencedirect.com/science/article/pii/S026 8005X18301565, [cited 2019 Sep 22]

\section{Publisher's Note}

Springer Nature remains neutral with regard to jurisdictional claims in published maps and institutional affiliations.

Ready to submit your research? Choose BMC and benefit from:

- fast, convenient online submission

- thorough peer review by experienced researchers in your field

- rapid publication on acceptance

- support for research data, including large and complex data types

- gold Open Access which fosters wider collaboration and increased citations

- maximum visibility for your research: over $100 \mathrm{M}$ website views per year

At $\mathrm{BMC}$, research is always in progress.

Learn more biomedcentral.com/submission 